\section{(6) OPEN ACCESS}

\title{
Epidemiology of silicosis: reports from the SWORD scheme in the UK from 1996 to 2017
}

\author{
Christopher Michael Barber, ${ }^{1}$ David Fishwick, ${ }^{1}$ Melanie Carder, ${ }^{2}$ Martie van Tongeren ${ }^{2}$
}

${ }^{1}$ Centre for Workplace Health, Health and Safety Laboratory, Buxton, UK

${ }^{2}$ Centre for Occupational and Environmental Health, University of Manchester, Manchester, UK

\section{Correspondence to}

Dr Christopher Michael Barber Centre for Workplace Health, Buxton, SK17 9JN, UK; chris.barber2@sth.nhs.uk

Received 4 July 2018 Revised 9 October 2018

Accepted 21 October 2018

Published Online First

10 November 2018
Check for updates

(c) Author(s) (or their employer(s)) 2019. Re-use permitted under CC BY-NC. No commercial re-use. See rights and permissions. Published by BMJ.

To cite: Barber CM,

Fishwick D, Carder M,

et al. Occup Environ Med

2019;76:17-21.

\section{ABSTRACT}

Objective To document the demographic risk factors of workers reported to have silicosis in the UK.

Methods All cases of silicosis reported to the

Surveillance of Work-related and Occupational Respiratory Disease (SWORD) scheme between January 1996 and December 2017 were classified into one of eight industry categories, and one of five age groups. In addition, to investigate whether there had been any temporal change, mean age and range at diagnosis was plotted for each year. From 2006, data were also available relating to the date of onset of symptoms, allowing a comparison between workers with and without respiratory symptoms.

Results For the period between 1996 and 2017, there were 216 cases of silicosis reported. The mean (range) age of those reported was 61 years (23-89), with the majority ( $98 \%$ ) being male. Across all industries, $65 \%$ of cases were diagnosed in individuals of working age $(<65$ for men and $<60$ for women). Silicosis was reported in young workers across all industry groups, with around one in six of all silicosis cases affecting workers under the age of 46 years. There was no clear trend in age of diagnosis with time. Between 2006 and 2017, $81 \%$ of 108 workers with silicosis were reported to be symptomatic.

Conclusions Silicosis remains an important health problem in the UK affecting workers of all ages across a wide range of industries traditionally associated with silica exposure.

\section{INTRODUCTION}

Silicosis remains an important global health problem, with disease attributed to established and new sources of exposure. ${ }^{2}$ The most common (chronic) form of silicosis usually occurs in older workers with many decades of low-level exposure. ${ }^{2}$ Over the last two decades, however, there have been a number of reports of acute or accelerated silicosis resulting in severe disability in younger workers. ${ }^{3-9}$ In some instances, this has resulted from poor levels of exposure control in industries with an established risk, such as Scottish stonemasons ${ }^{3}$ and US coal miners. ${ }^{4}$ In other cases, disease has resulted from new circumstances of exposure in dental technicians, ${ }^{56}$ jewellery workers, ${ }^{7}$ denim processors ${ }^{8}$ and fabricators of artificial-stone worktops. ${ }^{9}$ The risk of silicosis remains relevant to a number of UK industries, with an estimated 600000 silica exposed workers. $^{2}$

The aim of this study was to investigate the demographics of silicosis cases that have been reported to

\section{Key messages}

What is already known about this subject?

- Although recognised for many centuries, little is known about the epidemiology of silicosis in the UK.

\section{What are the new findings?}

- Over the last two decades, the number of new silicosis cases reported in the UK each year has been relatively static.

- The majority of reported UK cases originate from industrial sectors traditionally linked with silica exposure, and are diagnosed whilst they are of working age.

- Most cases of silicosis reported by secondary care physicians have respiratory symptoms, suggesting that they are not being diagnosed at an early stage.

\section{How might this impact on policy or clinical practice in the foreseeable future? \\ - Recent Great Britain surveillance guidance is likely to result in a significant change in national reporting patterns in the future, due to the increased utilisation of chest imaging.}

the Surveillance of Work-related and Occupational Respiratory Disease (SWORD), ${ }^{10}$ with a particular focus on the age of diagnosis across different industries.

\section{METHODS}

SWORD (established in 1989) is part of The Health and Occupation Research surveillance network. ${ }^{10}$ Chest physicians report voluntarily for either one randomly selected month per year ('sample' reporters) or for all 12 months of the year ('core' reporters). Physicians report incident (newly diagnosed) cases seen during their reporting month(s) that they judge to have been caused or aggravated by work; data recorded are diagnosis, age, gender, first half of postcode (area and district), industry, occupation, causal agent(s) and (from 2006) date of symptom onset. Occupation and industry are subsequently coded using the Standard Occupational Classification ${ }^{11}$ and Standard Industrial Classification (SIC), ${ }^{12}$ respectively. In addition to the 'actual' cases reported to SWORD (core cases plus sample cases), the number of 'estimated' cases is also calculated to allow for the different types of reporting pattern (sample cases multiplied by 12 plus core cases). 


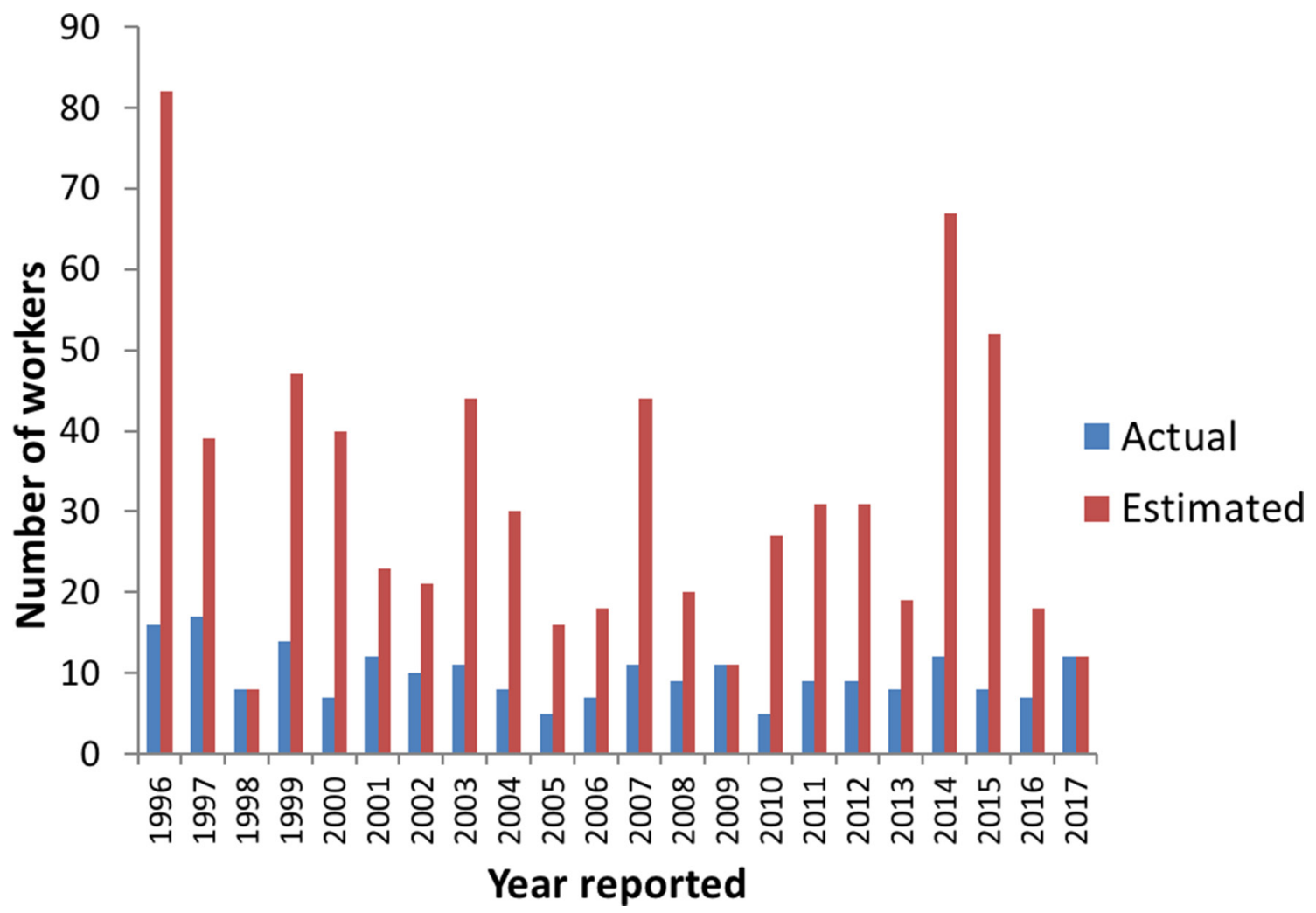

Figure 1 Actual and estimated number of silicosis cases reported to SWORD for each year between 1996 and 2017.

All actual cases of silicosis reported to the SWORD scheme between January 1996 and December 2017 were classified into one of eight industry categories based on SIC codes and one of five age groups. In addition, to investigate whether there had been any temporal change, mean age and age range at diagnosis were plotted for each year. Data relating to the date of onset of symptoms were used to separate patients into those with symptomatic and asymptomatic silicosis.

\section{RESULTS}

For the available 22-year SWORD reporting period, there were 216 actual reported cases of silicosis. Allowing for the pattern of reporting for core and sample reporters, this equated to an estimated 700 cases, that is, around 32 cases per year. The trend in number of actual and estimated silicosis cases is shown in figure 1.

For the actual reported cases of silicosis, mean age at diagnosis was 61 (range 23-89 years), and almost all (98\%) were male. Over the 22-year period, there was no clear trend in average age of diagnosis, which varied between 53 and 70 years (shown in figure 2).

When broken down into age categories (shown in figure 3), all industry groups included some younger cases (ie, under the age of 46). Overall, two-thirds of silicosis cases were diagnosed in individuals of working age ( $<65$ for men and $<60$ for women), with approximately one in six of all silicosis cases being diagnosed in younger workers.

The majority of reported silicosis cases (93\%) had occurred in one of seven industry groups traditionally associated with a known risk of silica exposure. Cases were relatively evenly spread between the industry groups, each contributing 7\%-21\% of the total, with the greatest number of workers coming from foundry/metal manufacturing (21\%) and quarrying (19\%). In 16 cases, silica exposure was classified as having occurred in an 'other' industry group. None of these workers had job titles or sources of exposure that suggested disease due to artificial-stone fabrication or processing clothing, but there were two cases of silicosis reported in dental technicians, and a further two cases in jewellery workers.

From 2006, SWORD reporters were asked to include a 'date of onset' of symptoms. For this 11-year period, there were 108 actual reported cases, with the majority (81\%) having

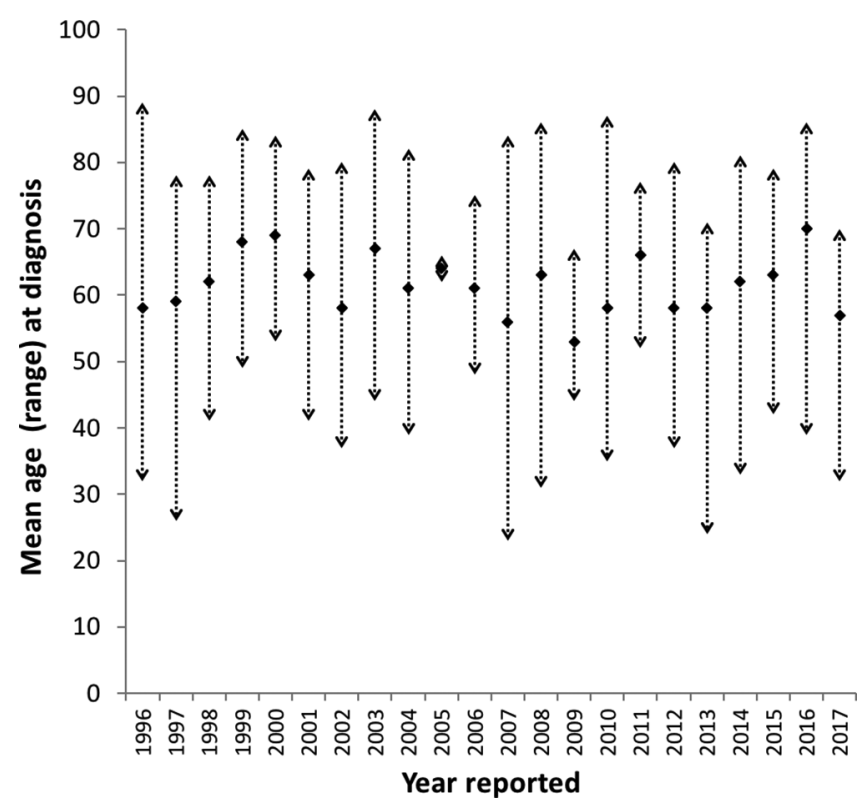

Figure 2 Mean age in years at diagnosis (with age range shown by arrowheads) of silicosis cases reported to SWORD for each year between 1996 and 2017. 


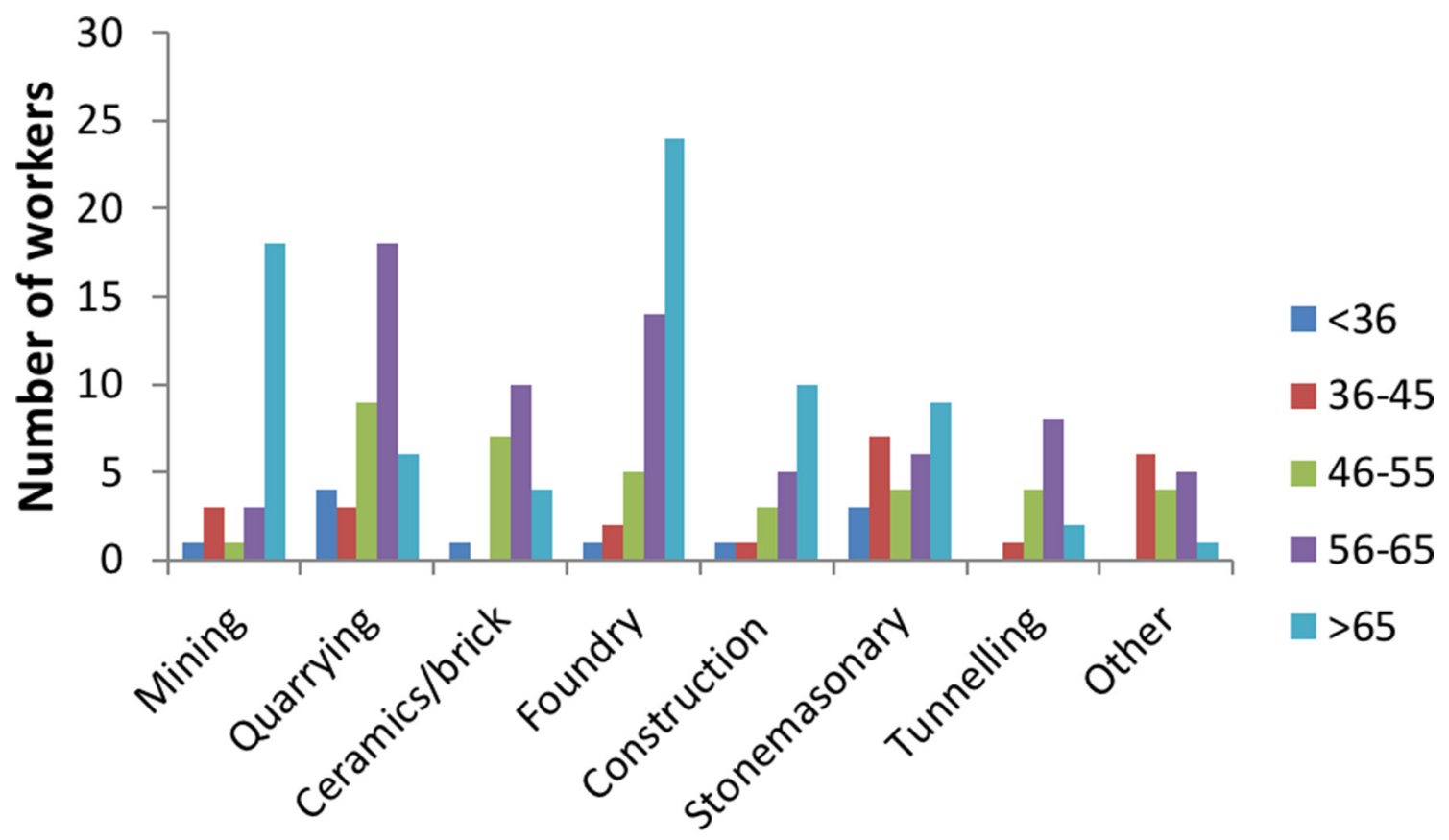

\section{Industry group}

Figure 3 Workers with silicosis reported to the SWORD scheme between 1996 and 2017, separated by age group and industry.

symptomatic silicosis. The numbers of workers in each industry group with and without reported symptoms are shown in figure 4. Small numbers of symptomatic younger workers (under the age of 46) were reported from each of the mining, quarrying, construction, stonemasonry, tunnelling and other industry groups.

\section{DISCUSSION}

This analysis is the first to detail the characteristics of silicosis cases that have been reported to the UK national reporting scheme over a long time period. During this time, the majority of reported cases had developed silicosis from working in an industry traditionally associated with silica exposure. No clear temporal trends were seen in either the number or the age range, of the actual cases reported each year, having analysed data from over 200 workers over a 22 -year period.

The limitations of using data from the SWORD reporting schemes have been discussed in detail elsewhere, ${ }^{13}$ particularly relating to the potential for underestimating disease incidence. In the case of silicosis, it is likely that this may be particularly

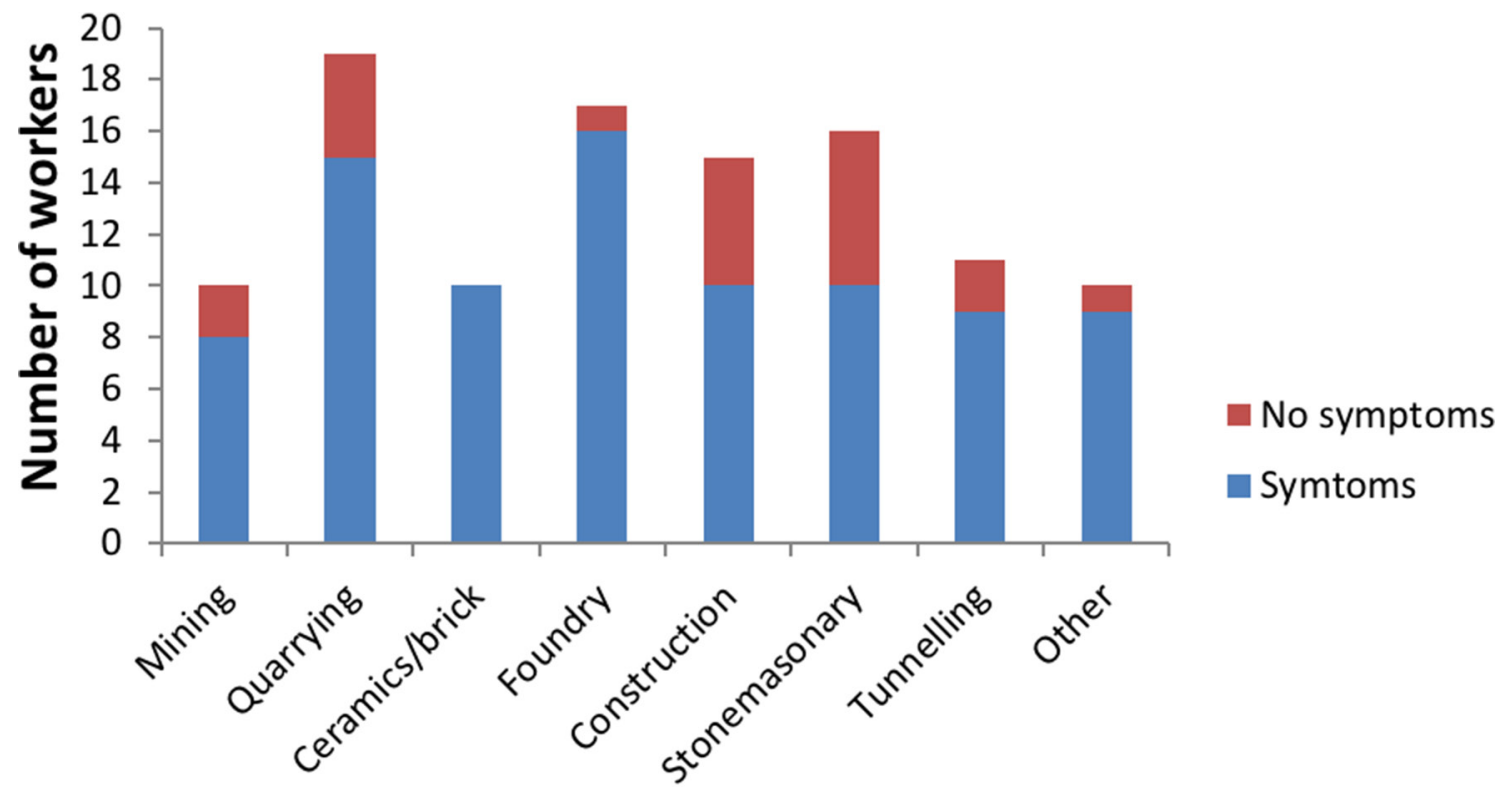

Industry group

Figure 4 Workers with symptomatic versus asymptomatic silicosis reported to the SWORD scheme between 2006 and 2017, separated by industry group. 
relevant, as the majority of the disease burden would be expected to be simple silicosis that is asymptomatic. The SWORD data estimate of 30-35 new cases per year from an exposed population of over half a million workers is therefore likely to be low, although it is impossible to calculate the expected incidence without an accurate knowledge of historical exposure levels. Silicosis is predominantly a long-latency disease, which makes calculating rates of disease challenging, without knowing the true 'at risk' industry population size that an individual case originated from over the period of their silica exposure. A recent analysis of SWORD data attempted to allow for this by using a notional 30-year lag period between first exposure and the development of silicosis, identifying high incidence rate ratios for miners and quarrymen, glass and ceramic makers and construction workers. ${ }^{14}$ Due to the inherent limitations of this approach, our analysis did not attempt to estimate incidence, focussing simply on the numbers of cases from each industry that have been diagnosed in secondary care. A high number of cases from an industry sector in our study may therefore be due to a greater risk of disease, or a higher number of exposed workers. We found that over $90 \%$ of all silicosis cases reported from secondary care had resulted from working in one of seven industry groups that have a well-established link to silica exposure. It is not possible however to ascertain from the SWORD data where the work in these industries occurred, either within or outside the UK.

The limited data requested by the SWORD scheme for each case are a further limitation, as it does not allow disease latency to be calculated, cannot differentiate between simple or complicated pneumoconiosis and does not record whether each silicosis case reflects acute, accelerated or chronic disease. Although the conclusions that can be drawn from these data are therefore somewhat limited, it seems reasonable to assume that a younger age of diagnosis and the presence of symptoms are valid markers of disease severity.

Data available for half of the reporting period found that almost all silicosis cases reported to SWORD had a recorded symptom-onset date, suggesting complicated disease that had been referred to secondary care. However, It is possible that the true proportion of complicated disease was even higher than that found in this analysis, due to our presumption that cases without a documented symptom-onset date had simple pneumoconiosis. In some cases, however, this presumption may have been incorrect, as missing data may have simply reflected incomplete reporting.

Chronic complicated silicosis typically develops over several decades of low-dose exposure, which fits with the average age of diagnosis (61 years) seen in our analysis. Although some cases were diagnosed after normal retirement age, the majority of workers reported to have silicosis were still of working age. A number of recent international reports have highlighted the risk of silicosis in younger workers, mainly due to the use of silica containing materials in newer occupational settings. Akgun et al reported 157 former denim sandblasters with silicosis in Turkey. ${ }^{8}$ All subjects were male and had a mean age of 23 years (range 15-44). Another recent study from Turkey highlighted the importance of silica exposure as a risk factor for dental technicians' pneumoconiosis. ${ }^{6}$ In this study, 90 cases were identified with a mean age of 35 years (SD 7). Most recently, Hoy et al reported seven male cases of artificial-stone silicosis from Australia, with a median age of 44 years (range 26-61). ${ }^{9}$ Although the mean age of diagnosis was higher for the SWORD cases over all, a significant proportion $(\sim 1$ in 6$)$ of all UK silicosis had been recognised in workers under the age of 46 years.
In all cases, the younger cases had worked in an industry traditionally associated with silica exposure, rather than reflecting newer sources of silica exposure. Four cases of silicosis were reported in jewellery or dental workers (two from each occupation), but none were diagnosed below the age of 50. Although none of the 'other' sources of exposure or associated job titles confirmed disease due to artificial stone, it is possible that any such cases could have been reported as having occurred among 'stonemasons'-an industry group with the highest proportion of younger workers.

Our study found that in some industry groups, particularly foundries and construction, there was an apparent increase in the number of cases with increasing age category. In contrast, in quarrying, tunnelling and the ceramic/brick industry groups this gradient was only seen in the subgroups of working-age patients, with a markedly lower number of cases reported in those over the age of 65 years. A completely different pattern was seen in miners, with two-thirds of cases being individuals of retirement age. Although it is likely that the pattern in miners relates to the decline of the UK mining industry, it is difficult to interpret the patterns seen in other industry groups, without a detailed understanding of how these industries have changed over time.

Updated silica health surveillance guidance for Great Britain was published by the Health and Safety Executive in 2016. ${ }^{15}$ This document provides clear and practical advice relating to the routine use of chest radiographs for silica-exposed workers, recommending X-rays after 15 years of exposure, and then every 3 years thereafter. It is likely therefore that an increased number of silica workers will undergo regular chest X-rays, resulting in more asymptomatic workers with simple silicosis being identified in the future. The findings of this analysis therefore represent baseline data, from which any significant demographic changes may be judged over the next decade.

Acknowledgements The authors are grateful to all physicians who report to SWORD.

Contributors $\mathrm{CMB}, \mathrm{MC}$ and MvT planned the study. $\mathrm{CMB}$ and $\mathrm{MC}$ contributed to data collection and analysis. All authors contributed to the writing, revision and approval of the final manuscript.

Funding SWORD is financially supported by the Health and Safety Executive in Great Britain (contract number PRJ500).

Disclaimer The contents of this publication reflect the views of the authors and not necessarily those of HSE policy.

Competing interests None declared.

Patient consent Not required.

Provenance and peer review Not commissioned; externally peer reviewed.

Open access This is an open access article distributed in accordance with the Creative Commons Attribution Non Commercial (CC BY-NC 4.0) license, which permits others to distribute, remix, adapt, build upon this work non-commercially, and license their derivative works on different terms, provided the original work is properly cited, appropriate credit is given, any changes made indicated, and the use is non-commercial. See: http://creativecommons.org/licenses/by-nc/4.0/.

\section{REFERENCES}

1 Sauvé JF. Historical and emerging workplaces affected by silica exposure since the 1930 Johannesburg conference on Silicosis, with special reference to construction. Am J Ind Med 2015;58:67-71.

2 Leung CC, Yu ITS, Chen W. Silicosis. The Lancet 2012;379:2008-18.

3 Nicol LM, McFarlane PA, Hirani N, et al. Six cases of silicosis: implications for health surveillance of stonemasons. Occup Med 2015;65:220-5.

4 Cohen RA, Petsonk EL, Rose C, et al. Lung Pathology in U.S. Coal Workers with Rapidly Progressive Pneumoconiosis Implicates Silica and Silicates. Am J Respir Crit Care Med 2016;193:673-80.

5 Orriols R, Ferrer J, Tura JM, et al. Sicca syndrome and silicoproteinosis in a dental technician. Eur Respir J 1997;10:731-4. 
6 Ergün D, Ergün R, Ozdemir C, et al. Pneumoconiosis and respiratory problems in dental laboratory technicians: analysis of 893 dental technicians. Int J Occup Med Environ Health 2014;27:785-96.

7 Murgia N, Muzi G, Dell'Omo M, et al. An old threat in a new setting: High prevalence of silicosis among jewelry workers. Am J Ind Med 2007;50:577-83.

8 Akgun $\mathrm{M}$, Araz 0, Akkurt I, et al. An epidemic of silicosis among former denim sandblasters. Eur Respir / 2008;32:1295-303.

9 Hoy RF, Baird T, Hammerschlag G, et al. Artificial stone-associated silicosis: a rapidly emerging occupational lung disease. Occup Environ Med 2018;75:3-5.

10 Meredith SK, Taylor VM, McDonald JC. Occupational respiratory disease in the United Kingdom 1989: a report to the British Thoracic Society and the Society of Occupational Medicine by the SWORD project group. Br J Ind Med 1991;48:292-8.
11 Office for National Statistics. Standard Occupational Classification 2000. London: The Stationery Office, 2000.

12 Office for National Statistics.. Standard Industrial Classification of Economic Activities 2007. Basingstoke: Palgrave Macmillan, 2009.

13 Carder M, McNamee R, Turner S, et al. Improving estimates of specialist-diagnosed, work-related respiratory and skin disease. Occup Med 2011;61:33-9.

14 Carder M, Darnton A, Gittins M, et al. Chest physician-reported, work-related, longlatency respiratory disease in Great Britain. Eur Respir J 2017;50:1700961.

15 Health surveillance for those exposed to respirable crystalline silica (RCS). Guidance for occupational health professionals. http://www.hse.gov.uk/pubns/books/ healthsurveillance.htm (Last accessed May 2018). 